\title{
Aelurostrongylus abstrusus Antibody Seroprevalence Reveals That Cats Are at Risk of Infection throughout Germany
}

\author{
Manuela Schnyder ${ }^{1, *(\mathbb{D}}$, Roland Schaper ${ }^{2} \mathbb{D}$, Francesca Gori $^{1}$, Carola Hafner ${ }^{3}$ and Christina Strube ${ }^{4}(\mathbb{D}$ \\ 1 Institute of Parasitology, Vetsuisse Faculty, University of Zurich, 8057 Zürich, Switzerland; \\ francesca.gori@uzh.ch \\ 2 Independent Researcher, 51381 Leverkusen, Germany; roland.schaper@gmx.de \\ 3 IDEXX, Vet Med Labor GmbH, 70806 Kornwestheim, Germany; Carola-Hafner@idexx.com \\ 4 Institute for Parasitology, Centre for Infection Medicine, University of Veterinary Medicine Hannover, \\ 30559 Hannover, Germany; christina.strube@tiho-hannover.de \\ * Correspondence: manuela.schnyder@uzh.ch
}

Citation: Schnyder, M.; Schaper, R.; Gori, F.; Hafner, C.; Strube, C.

Aelurostrongylus abstrusus Antibody Seroprevalence Reveals That Cats Are at Risk of Infection throughout Germany. Pathogens 2021, 10, 1011. https://doi.org/10.3390/ pathogens 10081011

Academic Editor: Eva Spada

Received: 10 June 2021

Accepted: 5 August 2021

Published: 10 August 2021

Publisher's Note: MDPI stays neutral with regard to jurisdictional claims in published maps and institutional affiliations.

Copyright: () 2021 by the authors. Licensee MDPI, Basel, Switzerland. This article is an open access article distributed under the terms and conditions of the Creative Commons Attribution (CC BY) license (https:// creativecommons.org/licenses/by/ $4.0 /)$.

\begin{abstract}
Cats infected with the metastrongylid nematode Aelurostrongylus abstrusus may show clinical signs ranging from mild to severe respiratory disease or remain unobserved, despite damages present in the lung tissue. This study aimed to determine the seroprevalence and distribution of $A$. abstrusus in cats by testing serum samples from all over Germany to identify potential risk areas and strengthen disease awareness accordingly. Sera of 2998 cats were screened for the presence of antibodies against $A$. abstrusus by ELISA, and the data were evaluated by a geographic information system to visualise the regional distribution of the analysed samples. Overall, $12.0 \%$ of the samples tested positive $(361 / 2998$ cats, $95 \%$ confidence interval: 10.9-13.3\%). Seropositive cats were identified throughout the country, suggesting that all cats in Germany with outdoor access are at risk of $A$. abstrusus infection and that the infection is overall underdiagnosed. Increased testing for A. abstrusus infection would allow earlier detection of infected animals, hence improving the life quality and health of cats and preventing potential death under anaesthesia.
\end{abstract}

Keywords: Aelurostrongylus abstrusus; feline lungworm; cat; Germany; antibody detection; ELISA; prevalence

\section{Introduction}

Aelurostrongylus abstrusus belongs to metastrongylid nematodes and is the most common feline lungworm worldwide being especially widespread across Europe [1]. Infected animals may show a range of clinical signs, from asymptomatic to severe respiratory distress. The most frequently observed signs are chronic cough, sneezing, nasal discharge, and dyspnea [2-5]. However, nonspecific signs or subclinical infections may also be observed [6,7], potentially leading to undiagnosed or misdiagnosed infections. Clinically apparent but asymptomatic infections with $A$. abstrusus should be considered seriously because lung tissue may be heavily affected by verminous pneumonia [8,9], even during prepatency [10]. Notably, such damages can lead to death during anaesthesia [11] and are therefore equally relevant in the frame of routine surgeries such as spaying and neutering.

The analysis of faecal samples by the Baermann technique is still the most frequently used diagnostic procedure to isolate and diagnose first-stage larvae (L1). This method relies on living L1 and, therefore, on fresh samples, as it is based on the principle of larval migration. Irregular or absent larval shedding, particularly in chronically and/or repeatedly infected cats, represents a further limitation [12-14].

Alternative diagnostic options have been described, including microscopic and cytologic examination of broncho-alveolar lavages [15], or, without anaesthesia, detecting parasite DNA from faecal or pharyngeal swab samples by PCR [16]. In addition, serological antibody detection was used recently for individual diagnosis and mass screening of cat populations [17-19]. However, A. abstrusus antibodies may not only be present 
before patency (i.e., 15 days post-infection) but also persist for weeks after successful anthelmintic treatment. In the latter case, antibody detection does not necessarily indicate a current infection [19]. Nevertheless, experimental and field data suggest a higher detection rate by serological procedures compared with copromicroscopic methods $[1,17,18,20]$, which can be explained by earlier onset and more consistent persistence of antibodies than larval production.

In the study presented here, we performed serological mass-screening of cats in Germany by a validated ELISA [19] to detect $A$. abstrusus infections. Previous studies suggested potential cross-reactions with other lungworms such as Troglostrongylus sp. [17,21,22]. In Germany, however, the detection of lungworms other than A. abstrusus in cats is very rare, except for Capillaria aerophila (syn. Eucoleus aerophilus). Prevalence data for A. abstrusus in Germany based on copromicroscopic examinations range from $0.5 \%$ to $2.7 \%$, and up to $6.6 \%$ in cats clinically suspected of $A$. abstrusus infection [23-28]. In contrast, C. aerophila was identified at a high prevalence $(69.4 \%)$ in red foxes [29], but not in cats, except for a study where the prevalence of Capillaria eggs was $1.0 \%$, although these could not be confirmed as C. aerophila eggs [26]. The latter species was identified in German wild cats (Felis silvestris silvestris), along with Troglostrongylus brevior and Angiostrongylus sp. [30], suggesting that these parasites occasionally occur in wild felids in the country.

This study aimed to determine the seroprevalence and potential geographic risk areas of $A$. abstrusus infection in cats by testing cat serum samples from all over the country to support targeted disease awareness and promote appropriate diagnostic procedures among veterinary practitioners.

\section{Results}

After analysing 2998 samples collected across Germany, an average seroprevalence of $12.0 \%$ (361/2998 cats, $95 \%$ confidence interval [CI]: 10.9-13.3\%) of A. abstrusus was determined. Seropositive cats were identified throughout the country (Figure 1), and there was a clear correlation between the number of analysed cats and the number of positive cats, indicating that no area can be considered free of A. abstrusus.

A larger number of samples $(>500)$ originated from Baden-Württemberg and Bavaria in southern Germany and North-Rhine Westphalia, the most western federal state of the country. In these regions, seroprevalences ranged from 9.0 to $14.8 \%$, with an overlapping 95\% CI (Table 1). Seroprevalences from other federal states ranged from 6.5\% (SaxonyAnhalt) to 32.0\% (Mecklenburg-West Pomerania), with large 95\% CIs. Therefore, no statistical difference between the federal states was observed.

Table 1. Number of serologically examined seropositive cats in federal states of Germany.

\begin{tabular}{|c|c|c|c|}
\hline Federal State of Germany & Number of Examined Sera (n) & Number of Positive Sera (n) & $\begin{array}{c}\text { Seroprevalence and } 95 \% \text { Confidence } \\
\text { Intervals ( } \% \text {, Range) }\end{array}$ \\
\hline Baden-Württemberg & 546 & 64 & $11.7(9.1-14.7)$ \\
\hline Bavaria & 548 & 77 & $14.1(11.3-17.2)$ \\
\hline Berlin & 105 & 9 & $8.3(4.0-15.6)$ \\
\hline Brandenburg & 110 & 14 & $12.7(7.1-20.4)$ \\
\hline Bremen & 17 & 4 & $23.5(6.8-49.9)$ \\
\hline Hamburg & 78 & 8 & $10.3(4.5-19.2)$ \\
\hline Hesse & 252 & 23 & $9.1(5.9-13.4)$ \\
\hline Mecklenburg-West Pomerania & 25 & 8 & $32.0(14.9-53.5)$ \\
\hline Lower Saxony & 186 & 20 & $10.8(6.7-16.1)$ \\
\hline North-Rhine Westphalia & 587 & 61 & $10.4(8.0-13.1)$ \\
\hline Rhineland Palatinate & 133 & 12 & $9.0(4.7-15.2)$ \\
\hline Saarland & 37 & 5 & $13.5(4.5-28.8)$ \\
\hline Saxony & 138 & 19 & $13.8(8.5-20.7)$ \\
\hline Saxony-Anhalt & 62 & 4 & $6.5(1.8-15.7)$ \\
\hline Schleswig-Holstein & 122 & 19 & $15.6(9.6-23.2)$ \\
\hline Thuringia & 52 & 14 & $26.9(15.6-41.0)$ \\
\hline Total & 2998 & 361 & $12.0(10.9-13.3)$ \\
\hline
\end{tabular}




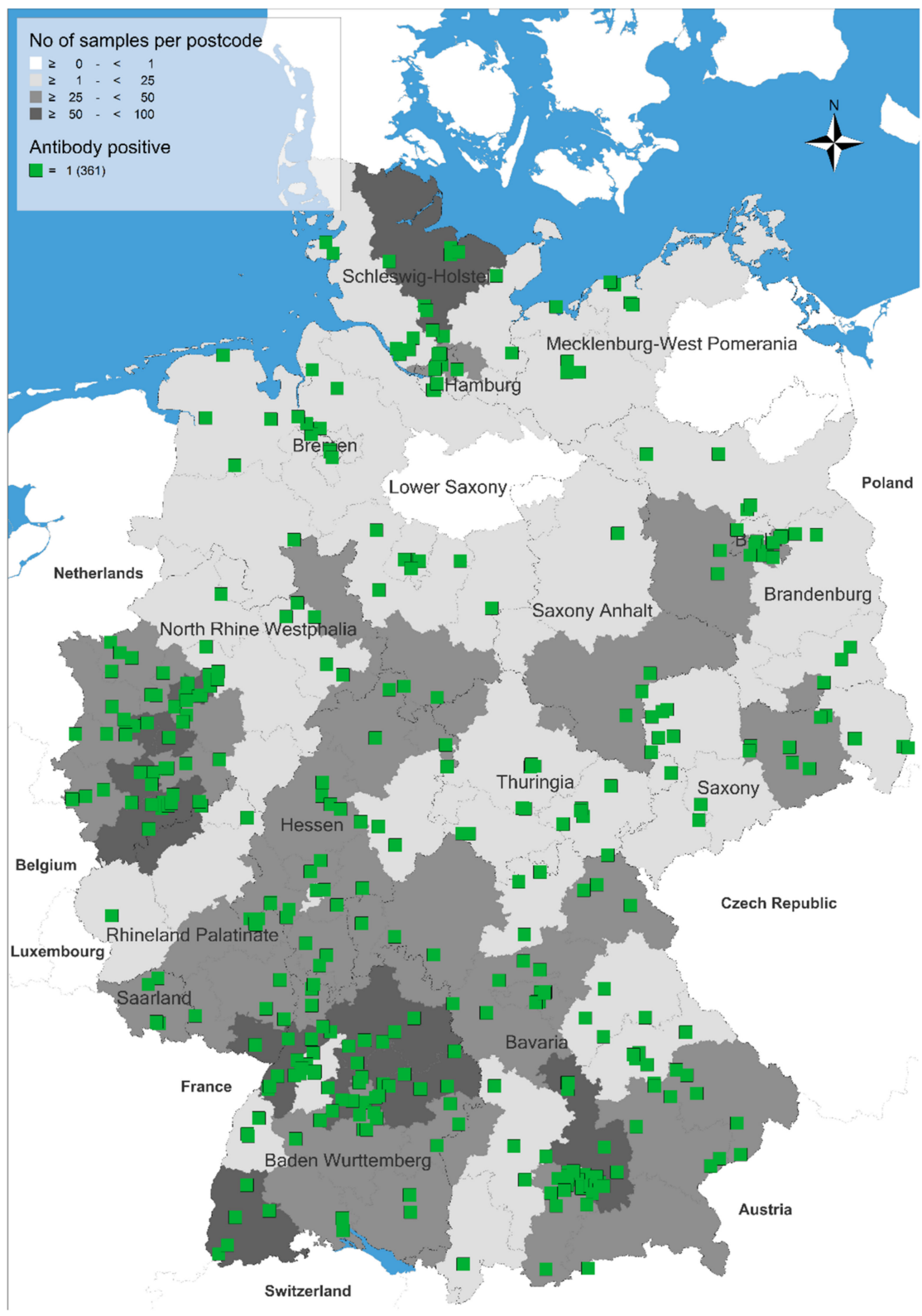

Figure 1. Occurrence of cats seropositive for antibodies against Aelurostrongylus abstrusus in Germany.

\section{Discussion}

With a seroprevalence of $12.0 \%$, the rate of $A$. abstrusus antibody-positive cats in Germany is clearly higher compared with previous data obtained by copromicroscopic methods. Past studies, based on a similar selection of cat samples, where the Baermann method was applied, indicated a prevalence of $2.7 \%$ in 3167 cats analysed between 1999 and 2002 [23], of $0.5 \%$ in 8560 cats analysed between 2003 and 2010 [26], and of $1.0 \%$ in 837 stray and foster cats sampled between 2006 and 2007 [27]. By contrast, selecting cats with symptoms of respiratory disease, $5.6 \%$ of 231 and $6.6 \%$ of 391 cats were coproscopically confirmed A. abstrusus positive between 2003 and 2007 [25], and between 2009 and 2011.

Overall, these results are comparable to data from Switzerland, a country bordering the south of Germany: 10.7\% of 4067 cats were seropositive for A. abstrusus antibodies [18], whereas between $0.8 \%$ and $2.3 \%$ of cats were coproscopically positive, with a higher prevalence in stray cats $(6.5 \%)$ than owned cats $(0.7 \%)$ [1,31]. Experimental studies showed that antibodies were detectable already 2-3 weeks before the onset of larval excretion [19], although isolated individuals may seroconvert later than 10 weeks post-infection [32]. Anti- 
bodies were then shown to persist as long as worms were present, therefore not necessarily correlating with patency [19]. Overall, a correlation between optical density (OD) values and the number of L1 per gram of faeces was observed, and it was concluded that low larval excretion may lead to OD values below the test threshold [32]. Antibodies also persisted for weeks after anthelmintic treatment [19,32]. By contrast, chronically infected cats or cats experiencing repeated infections (conceivable for all cats with unrestricted outdoor access) particularly showed an absence of larval shedding $[7,13,33]$, hence precluding diagnosis by the Baermann method; this consequently leads to higher sensitivity and detection rates obtained with serological testing. The latter observations have also been made within highly endemic areas in Italy [17].

Our data indicate that the parasite is present in all German federal states. There were no significant differences between the seroprevalences of the different federal states; however, within single states, there are apparent areas with higher local endemicity, particularly where a high number of samples were analysed (North-Rhine Westphalia, Baden-Württemberg and Bavaria). Interestingly, these areas, together with the neighbouring state of Saarland, also showed higher prevalence for canine lungworms Angiostrongylus vasorum and Crenosoma vulpis [34], both sharing the same gastropod intermediate hosts with A. abstrusus [35]. Endemicity likely correlates with the presence of intermediate hosts and, consequently, with a suitable climate for coprophagic gastropods [18]. Different gastropod species are considered suitable intermediate hosts for A. abstrusus, and, among them, Arion lusitanicus is a very common slug in central Europe. Of note, $0.4 \%$ of 1587 analysed snails and slugs collected in four different sites in Germany were $A$. abstrusus positive [35]. Since diverging risk and protective factors were identified for different canine lungworms [34], additional factors influencing A. abstrusus occurrence are expected. Wetlands and a higher density of wooded areas are considered advantageous for A. abstrusus establishment, in contrast with an increased percentage of paved surfaces with a loss of natural soil function, negatively influencing its occurrence, but altogether regionally influencing the number of available intermediate hosts [18]. Although it may be presupposed that gastropods need a rather humid environment, epidemiological and geoclimatic studies showed that $A$. abstrusus, with its large temperature tolerance, can establish itself worldwide. On one hand, A. abstrusus L1 were shown to survive repeated freezing and thawing [36]. On the other hand, warmer temperature conditions $\left(18-29^{\circ} \mathrm{C}\right)$ allowed a higher rate of larval development in intermediate hosts [37], premising sufficient humidity. In an earlier coproscopic study, positive cats were identified in the above-mentioned federal states and in northern Germany, but not in the centre of the country [28]. Therefore, increased A. abstrusus detection could therefore reflect either an increase of parasite occurrence over the years or be related to the low number of analysed samples between 2009-2011 [28]. Furthermore, considering the limited mobility of gastropods, additional support for establishment and dispersion is provided by potential interposed paratenic hosts such as rodents (i.e., Apodemus agrarius) [38] or reptiles, amphibians, and birds [39], probably feeding more frequently on gastropods than cats themselves. Therefore, it can be summarised that all cats with outdoor access may be at risk of infection in Germany, and in any A. abstrusus endemic area, provided that the geoclimatic factors are favourable.

Although serology cannot discriminate current infections from recently dewormed animals, the ELISA employed in the present work has the advantage of identifying positive cats with few or even absent clinical signs and, partially, before patency [18]. Compared with serology, a further disadvantage of L1 isolation from faecal samples is that it may be challenging to obtain such samples from cats, especially from free-ranging animals at high risk of infection. Further diagnostic tools may be used, reviewed in [40,41]. Diagnostic imaging, i.e., radiology and computed tomography, illustrates the onset of such damages despite the absence of clinical signs [8,32]. Infected cats may remain undetected by the animal owner for some time, or the clinical signs may be attributed to another respiratory disease, such as feline asthma, pulmonary oedema, neoplasia, or pneumonia-causing pathogens [2,42]. In both cases, the additional risk for lethal outcome exists if cats are subjected to anaesthesia: in $9 \%$ of cats whose death was associated with anaesthesia, lung 
tissue damages were caused by A. abstrusus [11]. Identifying infected cats by serology is therefore useful and relevant in symptomatic and asymptomatic animals, especially in view of the lung tissue damages induced by the parasite.

This risk is highly relevant considering that $12 \%$ of cats in Germany showed antibodies against $A$. abstrusus and that cats are frequently neutered, treated for abscesses or anesthetized for other reasons. Seroprevalences were actually almost twice as high in cats of some investigated Mediterranean areas, including Greece (27.3\%) and Italy (21.4\%, $22.5 \%)[17,21,22]$. Several factors influencing the risk of an individual cat becoming infected with $A$. abstrusus, partially contradictory, were described $[1,3,43,44]$. In summary, less well-cared-for cats with high roaming and hunting activity are at higher risk, directly or indirectly influenced by their neutering status and age [18]. In addition, it cannot be excluded that other infrequently occurring metastrongylid lungworms (Troglostrongylus sp. and Angiostrongylus sp.) identified in wild cats of Germany [30] may also infect domestic cats in the future, as observed in countries with higher endemicity. In Italy, a spillover from wild cats to domestic cats was observed for T. brevior [2], while Angiostrongylus chabaudi or Angiostrongylus vasorum is still very seldom found in domestic cats [45-47]. They all belong to the same taxonomic family, have a comparable life cycle, and may result in serological cross-reactions when testing for anti-A. abstrusus antibodies $[17,21]$. Capillaria spp. instead belong to the trichurids and are, thus, taxonomically distant from the metastrongylids and not expected to cross-react with them [19]. Therefore, serological detection of antibodies in German cats is currently expected to indicate A. abstrusus infection.

A fundamental advantage of this study is the use of serology, allowing efficient mass screening of cats; this is particularly valuable in the case of cats with outdoor access, where cats must be confined for the collection of faecal samples and Baermann analysis. Thus, it is easier for veterinary practitioners to collect a blood sample in case of clinical suspicion. A limiting factor of the study is the lack of information regarding anamnestic data and clinical signs of the investigated cats. However, advanced clinical signs often go undetected, and our data confirm that the infection is underestimated overall. This work highlights the benefit of increased testing for A. abstrusus infections in cats, with the goal of increasing disease awareness for a more accurate and earlier identification of infected animals prone to reduced quality of life and even death upon anaesthesia.

\section{Materials and Methods}

\subsection{Cat Sera}

Sera of 2998 cats from all over Germany submitted by veterinarians for haematological or clinical chemistry analyses and various other medical reasons were collected between November 2018 and March 2019. The sera were provided by IDEXX and sent to the Institute of Parasitology, University of Zurich in Switzerland.

\subsection{ELISA}

Serum samples were stored at $-20^{\circ} \mathrm{C}$ and thawed before being tested for antibodies against $A$. abstrusus by a previously described and validated indirect ELISA (sensitivity $88.2 \%$, specificity $90.0 \%$ ) [19]. The ELISA was performed with modifications: we used Nunc Immobilizer Amino Plates (Thermo Fisher Scientific, Roskilde, Denmark) coated with recombinant Dictyocaulus viviparus major sperm protein (MSP, $0.250 \mu \mathrm{g} /$ well), serum diluted 1:200, and a goat anti-feline IgG peroxidase-labelled conjugate (Southern Biotech, Birmingham, AL, USA) at a dilution of 1:9000. The absorbance values were read in a Multiscan ELISA reader (Tecan Infinite F50, Hombrechtikon, Switzerland), initially at $450 \mathrm{~nm}$ to determine the exact and optimal time to stop the reaction with sulphuric acid. Subsequently, the plate was read at $492 \mathrm{~nm}$. Each plate was run with a substrate control, two positive controls (sera from experimentally infected cats), two negative controls (uninfected laboratory cats) and a conjugate control. A reference serum was added twice to each plate to calculate a correction factor for adjustment between plates [48]. Test threshold (0.295) 
was determined with 300 randomly selected samples based on the mean value of optical density plus three standard deviations [49].

\subsection{Mapping, Statistical Analyses}

The collected data were analysed by a geographic information system (GIS) using the program RegioGraph 10 (GfK GeoMarketing, Bruchsal, Germany) to visualise the regional distribution of collected and analysed serum samples and A. abstrusus antibody-positive samples. Based on four digits as points of reference, the locations of positive samples were displayed on maps with administrative and postcode boundaries.

Excel 2016 for Windows (Microsoft Corporation, Redmond, WA, USA) was used to calculate the prevalence values, the $95 \% \mathrm{CI}$ and for calculating means and standard deviations (SD).

Author Contributions: Conceptualization, R.S. and M.S.; methodology, M.S., F.G., C.H. and C.S.; software, M.S., F.G. and R.S.; validation, M.S., F.G.; formal analysis, M.S., F.G.; investigation, C.H., F.G., R.S. and M.S.; resources, M.S., C.S. and R.S.; data curation, M.S., C.H., F.G. and R.S.; writingoriginal draft preparation, M.S.; writing—review and editing, M.S., C.S., C.H. and R.S.; visualization, R.S.; supervision, M.S.; project administration, M.S. All authors have read and agreed to the published version of the manuscript.

Funding: Financial support was provided by Bayer Animal Health GmbH and IDEXX. The Article Processing Charge was funded by Elanco Animal Health.

Institutional Review Board Statement: All animal and animal owner data were anonymised, and all investigations complied with the current laws of the countries in which they were performed.

Informed Consent Statement: Not applicable.

Data Availability Statement: Data supporting reported results is contained within the article.

Acknowledgments: The authors would like to thank Markus Reule for support with mapping and Yasemin Yaman from the Institute of Parasitology in Zurich for technical support.

Conflicts of Interest: R.S. was an employee of Bayer but has no direct or indirect financial interest in the subject matter discussed in the manuscript.

\section{References}

1. Giannelli, A.; Capelli, G.; Joachim, A.; Hinney, B.; Losson, B.; Kirkova, Z.; René-Martellet, M.; Papadopoulos, E.; Farkas, R.; Napoli, E.; et al. Lungworms and gastrointestinal parasites of domestic cats: A European perspective. Int. J. Parasitol. 2017, 47, 517-528. [CrossRef] [PubMed]

2. Crisi, P.E.; Aste, G.; Traversa, D.; Di Cesare, A.; Febo, E.; Vignoli, M.; Santori, D.; Luciani, A.; Boari, A. Single and mixed feline lungworm infections: Clinical, radiographic and therapeutic features of 26 cases (2013-2015). J. Feline Med. Surg. 2016, 19, 1017-1029. [CrossRef]

3. Genchi, M.; Ferrari, N.; Fonti, P.; De Francesco, I.; Piazza, C.; Viglietti, A. Relation between Aelurostrongylus abstrusus larvae excretion, respiratory and radiographic signs in naturally infected cats. Vet. Parasitol. 2014, 206, 182-187. [CrossRef]

4. Scott, D.W. Current knowledge of aelurostrongylosis in the cat. Literature review and case reports. Cornell Vet. 1973, 63, 483-500.

5. Traversa, D.; Lia, R.P.; Iorio, R.; Boari, A.; Paradies, P.; Capelli, G.; Avolio, S.; Otranto, D. Diagnosis and risk factors of Aelurostrongylus abstrusus (Nematoda, Strongylida) infection in cats from Italy. Vet. Parasitol. 2008, 153, 182-186. [CrossRef] [PubMed]

6. Hamilton, J. Production of immunity in the cat against lungworm disease by administration of third-stage larvae. J. Comp. Pathol. 1969, 79, 161-165. [CrossRef]

7. Schnyder, M.; Di Cesare, A.; Basso, W.; Guscetti, F.; Riond, B.; Glaus, T.M.; Crisi, P.; Deplazes, P. Clinical, laboratory and pathological findings in cats experimentally infected with Aelurostrongylus abstrusus. Parasitol. Res. 2014, 113, 1425-1433. [CrossRef] [PubMed]

8. Dennler, M.; Bass, D.A.; Gutierrez-Crespo, B.; Schnyder, M.; Guscetti, F.; Di Cesare, A.; Deplazes, P.; Kircher, P.; Glaus, T.M. Thoracic computed tomography, angiographic computed tomography, and pathology findings in six cats experimentally infected with Aelurostrongylus abstrusus. Vet. Radiol. Ultrasound 2013, 54, 459-469. [CrossRef]

9. Hamilton, J. Experimental lungworm disease of the cat. J. Comp. Pathol. 1966, 76, 147-157. [CrossRef]

10. Stockdale, P. The pathogenesis of the lesions elicited by Aelurostrongylus abstrusus during its prepatent period. Pathol. Vet. 1970, 7, 102-115. [CrossRef] [PubMed] 
11. Gerdin, J.A.; Slater, M.R.; Makolinski, K.V.; Looney, A.L.; Appel, L.D.; Martin, N.M.; McDonough, S.P. Post-mortem findings in 54 cases of anesthetic associated death in cats from two spay-neuter programs in New York State. J. Feline Med. Surg. 2011, 13, 959-966. [CrossRef] [PubMed]

12. Hamilton, J.M. Studies on re-infestation of the cat with Aelurostrongylus abstrusus. J. Comp. Pathol. 1968, 78, 69-72. [CrossRef]

13. Ribeiro, V.M.; Lima Dos Santos, W. Larval production of cats infected and re-infected with Aelurostrongylus abstrusus (Nematoda: Protostrongylidae). Rev. Méd. Vét. 2001, 152, 815-820.

14. Schnyder, M.; Fahrion, A.; Ossent, P.; Kohler, L.; Webster, P.; Heine, J.; Deplazes, P. Larvicidal effect of imidacloprid/moxidectin spot-on solution in dogs experimentally inoculated with Angiostrongylus vasorum. Vet. Parasitol. 2009, 166, 326-332. [CrossRef]

15. Foster, S.; Martin, P.; Braddock, J.; Malik, R. A retrospective analysis of feline bronchoalveolar lavage cytology and microbiology (1995-2000). J. Feline Med. Surg. 2004, 6, 189-198. [CrossRef]

16. Traversa, D.; Iorio, R.; Otranto, D. Diagnostic and Clinical implications of a nested PCR specific for ribosomal DNA of the feline lungworm Aelurostrongylus abstrusus (Nematoda, Strongylida). J. Clin. Microbiol. 2008, 46, 1811-1817. [CrossRef] [PubMed]

17. Di Cesare, A.; Gueldner, E.K.; Traversa, D.; Veronesi, F.; Morelli, S.; Crisi, P.E.; Pampurini, F.; Strube, C.; Schnyder, M. Seroprevalence of antibodies against the cat lungworm Aelurostrongylus abstrusus in cats from endemic areas of Italy. Vet. Parasitol. 2019, 272, 13-16. [CrossRef]

18. Gueldner, E.K.; Gilli, U.; Strube, C.; Schnyder, M. Seroprevalence, biogeographic distribution and risk factors for Aelurostrongylus abstrusus infections in Swiss cats. Vet. Parasitol. 2019, 266, 27-33. [CrossRef]

19. Zottler, E.-M.; Strube, C.; Schnyder, M. Detection of specific antibodies in cats infected with the lung nematode Aelurostrongylus abstrusus. Vet. Parasitol. 2017, 235, 75-82. [CrossRef]

20. Traversa, D.; Morelli, S.; Cassini, R.; Crisi, P.E.; Russi, I.; Grillotti, E.; Manzocchi, S.; Simonato, G.; Beraldo, P.; Viglietti, A.; et al. Occurrence of canine and feline extra-intestinal nematodes in key endemic regions of Italy. Acta Trop. 2019, 193, 227-235. [CrossRef]

21. Cavalera, M.A.; Schnyder, M.; Gueldner, E.K.; Furlanello, T.; Iatta, R.; Brianti, E.; Strube, C.; Colella, V.; Otranto, D. Serological survey and risk factors of Aelurostrongylus abstrusus infection among owned cats in Italy. Parasitol. Res. 2019, 118, $2377-2382$. [CrossRef] [PubMed]

22. Morelli, S.; Diakou, A.; Di Cesare, A.; Schnyder, M.; Colombo, M.; Strube, C.; Dimzas, D.; Latino, R.; Traversa, D. Feline lungworms in Greece: Copromicroscopic, molecular and serological study. Parasitol. Res. 2020, 119, 2877-2883. [CrossRef]

23. Barutzki, D.; Schaper, R. Endoparasites in dogs and cats in Germany 1999-2002. Parasitol. Res. 2003, 90, S148-S150. [CrossRef]

24. Barutzki, D.; Schaper, R. Natural infections of Angiostrongylus vasorum and Crenosoma vulpis in dogs in Germany (2007-2009). Parasitol. Res. 2009, 105, 39-48. [CrossRef] [PubMed]

25. Taubert, A.; Pantchev, N.; Vrhovec, M.G.; Bauer, C.; Hermosilla, C. Lungworm infections (Angiostrongylus vasorum, Crenosoma vulpis, Aelurostrongylus abstrusus) in dogs and cats in Germany and Denmark in 2003-2007. Vet. Parasitol. 2009, 159, 175-180. [CrossRef]

26. Barutzki, D.; Schaper, R. Results of parasitological examinations of faecal samples from cats and dogs in Germany between 2003 and 2010. Parasitol. Res. 2011, 109, 45-60. [CrossRef]

27. Becker, A.-C.; Rohen, M.; Epe, C.; Schnieder, T. Prevalence of endoparasites in stray and fostered dogs and cats in Northern Germany. Parasitol. Res. 2012, 111, 849-857. [CrossRef]

28. Barutzki, D.; Schaper, R. Occurrence and regional distribution of Aelurostrongylus abstrusus in cats in Germany. Parasitol. Res. 2012, 112, 855-861. [CrossRef] [PubMed]

29. Schug, K.; Kramer, F.; Schaper, R.; Hirzmann, J.; Failing, K.; Hermosilla, C.; Taubert, A. Prevalence survey on lungworm (Angiostrongylus vasorum, Crenosoma vulpis, Eucoleus aerophilus) infections of wild red foxes (Vulpes vulpes) in central Germany. Parasites Vectors 2018, 11, 85. [CrossRef]

30. Steeb, S.; Hirzmann, J.; Eskens, U.; Volmer, K.; Bauer, C. Lungenwurm-Infektionen bei der europäischen Wildkatze. Kompakt Vet. 2014, 3, 9 .

31. Zottler, E.-M.; Bieri, M.; Basso, W.; Schnyder, M. Intestinal parasites and lungworms in stray, shelter and privately owned cats of Switzerland. Parasitol. Int. 2018, 69, 75-81. [CrossRef] [PubMed]

32. Raue, K.; Raue, J.; Hauck, D.; Söbbeler, F.; Morelli, S.; Traversa, D.; Schnyder, M.; Volk, H.; Strube, C. Do all roads lead to Rome? The potential of different approaches to diagnose Aelurostrongylus abstrusus infection in cats. Pathogens 2021, 10, 602. [CrossRef] [PubMed]

33. Hamilton, J.M.; McCaw, A.W. The output of first stage larvae by cats infested with Aelurostrongylus abstrusus. J. Helminthol. 1968, 42, 295-298. [CrossRef]

34. Maksimov, P.; Hermosilla, C.; Taubert, A.; Staubach, C.; Sauter-Louis, C.; Conraths, F.J.; Vrhovec, M.G.; Pantchev, N. GISsupported epidemiological analysis on canine Angiostrongylus vasorum and Crenosoma vulpis infections in Germany. Parasites Vectors 2017, 10, 108. [CrossRef]

35. Lange, M.; Penagos-Tabares, F.; Hirzmann, J.; Failing, K.; Schaper, R.; Van Bourgonie, Y.; Backeljau, T.; Hermosilla, C.; Taubert, A. Prevalence of Angiostrongylus vasorum, Aelurostrongylus abstrusus and Crenosoma vulpis larvae in native slug populations in Germany. Vet. Parasitol. 2018, 254, 120-130. [CrossRef]

36. Hamilton, J.M.; McCaw, A.W. An investigation into the longevity of first stage larvae of Aelurostrongylus abstrusus. J. Helminthol. 1967, 41, 313-320. [CrossRef] 
37. Di Cesare, A.; Crisi, P.E.; Bartolini, R.; Iorio, R.; Talone, T.; Filippi, L.; Traversa, D. Larval development of Angiostrongylus vasorum in the land snail Helix aspersa. Parasitol. Res. 2015, 114, 3649-3655. [CrossRef] [PubMed]

38. Jeżewski, W.; Buńkowska-Gawlik, K.; Hildebrand, J.; Perec-Matysiak, A.; Laskowski, Z. Intermediate and paratenic hosts in the life cycle of Aelurostrongylus abstrusus in natural environment. Vet. Parasitol. 2013, 198, 401-405. [CrossRef]

39. Hobmaier, M.; Hobmaier, A. Intermediate hosts of Aelurostrongylus abstrusus of the cat. Exp. Biol. Med. 1935, 32, 1641-1647. [CrossRef]

40. Elsheikha, H.M.; Schnyder, M.; Traversa, D.; Di Cesare, A.; Wright, I.; Lacher, D.W. Updates on feline aelurostrongylosis and research priorities for the next decade. Parasites Vectors 2016, 9, 389. [CrossRef] [PubMed]

41. Morelli, S.; Diakou, A.; Colombo, M.; Di Cesare, A.; Barlaam, A.; Dimzas, D.; Traversa, D. Cat respiratory nematodes: Current knowledge, novel data and warranted Studies on clinical features, treatment and control. Pathogens 2021, 10, 454. [CrossRef] [PubMed]

42. Foster, S.; Martin, P.; Allan, G.; Barrs, V.; Malik, R. Lower respiratory tract infections in cats: 21 cases (1995-2000). J. Feline Med. Surg. 2004, 6, 167-180. [CrossRef] [PubMed]

43. Beugnet, F.; Bourdeau, P.; Chalvet-Monfray, K.; Cozma, V.; Farkas, R.; Guillot, J.; Halos, L.; Joachim, A.; Losson, B.; Miró, G.; et al. Parasites of domestic owned cats in Europe: Co-infestations and risk factors. Parasites Vectors 2014, 7, 291. [CrossRef]

44. Hansen, A.P.; Skarbye, L.K.; Vinther, L.M.; Willesen, J.; Pipper, C.B.; Olsen, C.S.; Mejer, H. Occurrence and clinical significance of Aelurostrongylus abstrusus and other endoparasites in Danish cats. Vet. Parasitol. 2017, 234, 31-39. [CrossRef] [PubMed]

45. Gueldner, E.K.; Schuppisser, C.; Borel, N.; Hilbe, M.; Schnyder, M. First case of a natural infection in a domestic cat (Felis catus) with the canid heart worm Angiostrongylus vasorum. Vet. Parasitol. Reg. Stud. Rep. 2019, 18, 100342. [CrossRef] [PubMed]

46. Varcasia, A.; Tamponi, C.; Brianti, E.; Cabras, P.A.; Boi, R.; Pipia, A.P.; Giannelli, A.; Otranto, D.; Scala, A. Angiostrongylus chabaudi Biocca, 1957: A new parasite for domestic cats? Parasites Vectors 2014, 7, 588. [CrossRef] [PubMed]

47. Di Cesare, A.; Morelli, S.; Colombo, M.; Simonato, G.; Veronesi, F.; Marcer, F.; Diakou, A.; D'Angelosante, R.; Pantchev, N.; Psaralexi, E.; et al. Is Angiostrongylosis a Realistic Threat for Domestic Cats? Front. Vet. Sci. 2020, 7. [CrossRef] [PubMed]

48. Schnyder, M.; Tanner, I.; Webster, P.; Barutzki, D.; Deplazes, P. An ELISA for sensitive and specific detection of circulating antigen of Angiostrongylus vasorum in serum samples of naturally and experimentally infected dogs. Vet. Parasitol. 2011, 179, 152-158. [CrossRef]

49. Schnyder, M.; Schaper, R.; Bilbrough, G.; Morgan, E.; Deplazes, P. Seroepidemiological survey for canine angiostrongylosis in dogs from Germany and the UK using combined detection of Angiostrongylus vasorum antigen and specific antibodies. Parasitology 2013, 140, 1442-1450. [CrossRef] [PubMed] 